\title{
Sign theory at work: The mental imagery debate revisited
}

\author{
Jelena Issajeva \\ Chair of Philosophy, Tallinn University of Technology \\ Akadeemia tee 3, 12618 Tallinn, Estonia \\ e-mail: jelena.issajeva@gmail.com
}

\begin{abstract}
This article attempts to give a plausible explanation to the long-debated question about the nature of mental imagery (MI). The traditional approach to this question is based on the representational paradigm, which, I claim, is misguided. Instead of representational aspects of mental imagery, I emphasize the functions of mental imagery, the variety of properties that images exhibit in experimental studies, and the relations between different characteristics of images, their functions and the subject of imagery. That is, I propose to account for mental imagery as a sign system, consisting of different types of signs. A mental image can contain important properties as parts of the complex sign. This approach to the explanation of the nature of MI is beneficial, since it suggests the phenomenon of mental imagery, which overcomes some long-standing controversies on the issue.
\end{abstract}

Keywords: mental imagery, internal representations, imagery debate, sign theory, Charles Peirce, semiotics, sign relations, classification of signs, cognition

\section{Introduction}

What is a mental image? This question remains one of the most debated ones in cognitive psychology, cognitive sciences and the philosophy of the mind. On the one hand, it seems quite evident that a mental image looks like something, i.e. it is a mental picture. We seem to exploit picture-like representations while imagining, remembering or dreaming about something. In this vein, Stephen Kosslyn, for example, has experimentally shown that mental imagery (MI) indeed has certain spatial and picture-like properties that can legitimately be treated as pictures in the mind's eye (Kosslyn 1980, 1988, 1994; Kosslyn et al. 2006). On the other hand, however, we are also forced to admit that mental images take propositional forms analogous to languages (Pylyshyn 1973, 2002, 2003, 2006). Still, as the empirical research results in ambiguous conclusions, the problem 
of the nature of MI remains - what is mental imagery really like? Is it a picture in the brain, some propositional or verbal string of language-like characteristics or symbols, or something else yet?

In this article I am going to argue for that third (and promising) way to analyse mental imagery: namely to treat it as a system of signs. This paper starts with a brief discussion of the underlying assumptions of that approach, setting out the context for the problem of MI. Then in Section 2 I proceed with the explanation for why mental imagery is viewed as a sign system. In particular, Section 2.1 explains why a mental image can be viewed as a sign, supported by theoretical considerations. Finally, in Section 2.2 I argue that sign theory, applied to the analysis of mental images, suggests a viable interpretation of the MI phenomenon. In particular, I consider an example of an ordinary daydream in terms of a theory of signs. The analysis is intended to show that the MI phenomenon is better accounted for in terms of signs than in terms of pictures or language. My interpretation of mental images suggests an explanation of the MI phenomenon that overcomes controversies characterizing the field while avoiding typical problems concerning representational theories about MI.

\section{The theoretical assumptions}

The question about the nature of MI is typically based on the search for particular (or dominant) formats of mental representation, plus the manner in which this representation is formed and further operated on. From such a perspective, two main answers to the question of what MI is can be given: either MI is a picture-like representation or a language-like representation. It is no surprise that these two theses, both influential in the research of MI, are somewhat contrary to each other. It is these two postulates that underlie most empirical research on the MI phenomenon, either explicitly (as in Kosslyn et al. 2003 or Pylyshyn 2002) or implicitly (as in music studies, sport studies etc.). It is this irreducible controversy between the two theses that makes the MI Debate ${ }^{1}$ seem almost insoluble.

But what if the question about the ultimate format of mental images or internal representations is, in itself, ambiguous? Are the two formats necessarily mutually exclusive? Indeed, it seems that we do possess both kinds of mental entities - pictorial/ analogue and propositional/verbal. Why should there be only one kind of MI? Recent

\footnotetext{
1 By the Mental Imagery Debate, also called the analogue-propositional debate, I mean the ongoing dispute concerning the representational format of MI. The analogue, or quasi-pictorial, theory holds that images are ultimately picture-like, with intrinsically spatial representational properties. The propositional account, on the contrary, interprets mental images to be similar to linguistic descriptions.
} 
experimental results also support the conclusion that mental imagery (in a number of experimental settings) can exhibit both types of properties, verbal and pictorial (see, e.g., Bartolomeo 2002, 2008). How to interpret such findings? The understanding of MI should not, it seems, be restricted to the plain dichotomy of verbal vs. pictorial. There is a significant amount of empirical data clearly showing the existence of motor, tactile and auditory properties of mental imagery (Keller 2012; Pascual-Leone et al. 1995; Richardson 1995). ${ }^{2}$ No doubt much of the latter cannot be analysed and explained in verbal vs. pictorial terms. The discussions concerning the ultimate format of mental images fail to explain why experimental evidence on MI is so ambivalent.

The assumptions underlying what constitutes the MI phenomenon are, I believe, misguided. Instead of the format of mental imagery, one ought to look at the functions of mental imagery, the variety of properties that images exhibit in experiments, the relations between different characteristics of images and their functions, and the subject who employs the MI.

To investigate MI only from the perspective of its format is to narrow down and limit the scope of the research. The information that scientists get from controlled experiments given the format assumption suggests only partial explanations to MI. This actually happens when one attempts to explain new empirical evidence. The experiments directed at investigating a particular format of MI inevitably neglect other features, properties, possible explanations and intrinsic relations that might be essential parts of the mental phenomenon. That is, experiments tend to neglect other perspectives on understanding MI. However, if we place the experimental results concerning $\mathrm{MI}$ into the broader context of properties and relations in which particular images were formed and used, we might get more information regarding its nature.

In other words, the analysis of MI that ceases to be driven by the constraints of the representational, or the computational, paradigms $s^{3}$ opens up new possibilities. How does MI appear to us? That is, exactly how do we experience mental imagery? When employing imagery in daily life, one notices that mental representations can have a variety of divergent properties: they can have colours, textures, shapes, sizes and so on. Or else they abstract from such properties and become something like general and more or less indefinite ideas.

2 See also Plessinger, Anne 2007. The effects of mental imagery on athletic performance. At: http://healthpsych.psy.vanderbilt.edu/HealthPsych/mentalimagery.html.

3 Until recently, it was the computational paradigm that was the leading theory in cognitive sciences and widely acknowledged to underlie the representational accounts of MI (see, e.g., Kosslyn 1980; Fodor 1975; Glasgow, Papadias 1992, as well as Thomas, Nigel J. T. 2014. Mental imagery. In: Zalta, Edward N. (ed.), The Stanford Encyclopedia of Philosophy (Fall 2014 ed.), available at: http://plato.stanford.edu/archives/fall2014/entries/mental-imagery/). The main adherents of the pictorial-imagery theory explicitly expressed their commitment to the computational paradigm (Kosslyn 1980, 1994; Kosslyn et al. 2006). 
How is it possible that we can have both detailed and abstract images, either at different times or even occurring in the same experienced MI phenomenon? For example, when someone dreams of some future event that has not happened yet, she from one perspective engages in an imaginary experience full of details of how the event could or would be. On the other hand, part of this complex and multidimensional process remains abstract and imprecise. For instance, she might mentally draw the connections between various parts of her dreams (say, how she would get at what she imagined or dreamed about) in those abstract terms. But she might employ a vivid and detailed picture-like image in which she imagines what the final goal of her dream looks like. To put it simply, she might experience some parts of her dream in words, yet other parts in pictures. Does it mean that her dream ceases to be imaginary, if it fails to fully fall within the scope of one of the two dominant formats?

One could say that an ordinary daydream ${ }^{4}$ might just be the sum of the representations of either type. Yet if this were the case, one would encounter difficulties in explaining the variety of divergent properties engaged in a daydream from the perspective of a single format. And even if we for a moment leave aside the limitations of a dominant format account of MI, then how can the interconnections between different parts, characteristics and properties of the images be explained? Furthermore, how is the meaning of the daydream as a whole explained?

It seems that a dream is not just the mere sum of its constituent parts and their properties. It has something more, a meaning as a whole; it is something of its own. The sum total of random presentations is not yet a dream; it will not have the systematic structure and meaning required of one. In a similar vein, MI could be treated as a complex system of signs and their properties, ${ }^{5}$ which can be combined and detached from one another, associated and manipulated voluntarily by our mind in various ways, and so on. Viewing MI as a sign system solves many problems.

It is worth noting that the interpretation of the image in terms of signs is compatible with the traditional representational accounts of MI, according to which MI is the

\footnotetext{
4 By 'day-dream' I mean a voluntary conscious flow of images that are not based on the respective physical stimuli.

5 The definition of mental imagery as a "complex system of signs and their properties" needs some additional clarification. By 'system' I mean here a set of elements and relations that work together as a whole and constitute an interconnected network, which is guided by general rules of semiosis, i.e. by the signifying process. I call the system 'complex', because of the manylevelled and manifold relations and elements it includes. Firstly, this system of signs has several elements: representamen, object, interpretant and subject. Secondly, the system has several levels of relations: (1) between the relata; (2) in respect to each element of the sign; (3) in respect to the subject. For these reasons I call the sign system "complex". Finally, the 'property' is used here in a broader sense to denote various characteristics of signs, such as iconicity, indexicality and symbolicity.
} 
internal representation of a particular format. In other words, both quasi-pictorial and propositional accounts focus only on one element of the sign, namely on the representamen ${ }^{6}$ (or the sign vehicle) of the image, thus equating the very image with this one element. The centre of the analysis and investigation of the image shifts to the particular format of the representamen: does it have pictorial properties and constitute a picture in the mind, or does it have verbal properties and a propositional format? Such analysis necessarily restricts the investigation and understanding of the mental-imagery phenomenon, because (1) it takes the image out of the context of relations where it was formed and employed; and (2) it neglects the other two elements of the image - its object and meaning (which will be discussed later in more detail). We cannot truly understand the representamen without understanding the object it represents and the meaning that such representation conveys. A full-fledged understanding of the nature of an image is only possible when $\mathrm{MI}$ is viewed within the complex context of relations between the three relata. In this sense, an interpretation of $\mathrm{MI}$ in terms of sign systems broadens the understanding of mental imagery, accounted solely in terms of representation before.

Yet another difference between viewing mental imagery as a sign system in comparison with representation lies in the following: the representational account of MI sees an image as a stable, more or less fixed mental entity (be it a picture or a word) ready for retrieval and manipulation, whereas the understanding of MI as a sign goes beyond that. It views the mental image as a dynamic, ${ }^{7}$ continuous and changing mental entity which can only be accounted for within the context of the relations and cognitive processes it is engaged in. This complex contextuality of MI means changing the nature and the dynamics in the usage of mental imagery to solve cognitive tasks.

\section{Mental imagery as a sign system}

In order to understand to what extent we can talk about mental images as mental signs, it is useful to begin with the brief explanation of what a sign is and how it

\footnotetext{
6 The fundamental difference between the representamen and representation, as considered with regard to mental imagery, is that the former is only one part of the triadic sign relation, whereas in the latter case, the image is identified only as a representation.

7 The terms 'stable' and 'dynamic' are opposites. By the term 'stable' I mean a fixed, essentially unchangeable mental entity whose nature and properties remain the same despite changing the context or changing the way of its retrieval. By 'dynamic' I mean an open and changeable mental entity whose properties change when the context or the relations between its various parts are changed.
} 
functions in the mind. ${ }^{8}$ According to Peirce, ${ }^{9}$ a sign is "something which stands to somebody for something in some respect or capacity. It addresses somebody, that is, creates in the mind of that person an equivalent sign, or perhaps a more developed sign. That sign which it creates I call the interpretant of the first sign. The sign stands for something, its object" (CP 2.228). This definition uncovers two main aspects of a sign: (1) Peirce defines a sign through its participation in a semiotic or signifying process (i.e. semiosis); (2) and he views a sign as consisting of three relata or three basic elements - a sign itself or signifying vehicle or representamen (as Peirce sometimes calls it), an object which the sign stands for and an interpretant ${ }^{10}$ as the meaning of the relation between the signifying vehicle and its object. The sign, its structure and nature, is about the semiotic relations between its three elements.

\subsection{Why can a mental image be a sign?}

What is the rationale for treating mental imagery as a sign system? The main reason to account for mental imagery as a sign system and mental image as a sign, respectively, is that the mental image has a trichotomic structure, functions and properties that are similar to those of signs.

Firstly, if we analyse the mental image outside of any particular premise or hypothesis, the very first characteristic that we will notice is the intentionality ${ }^{11}$ of images. In short, an image is necessarily about something, or it is directed towards some object. It seems every image (of whatever kind) that the human mind produces is about

8 The question of the signifying nature of mental imagery inevitably leads us to the question of the signifying nature of the mind in general. Peirce, for example, held that the mind indeed has a signifying nature, i.e. all our mental and cognitive capacities are by means of signs. However, the analysis and discussion of this more general claim is outside the scope of the present paper.

9 Many sign theories have been suggested (e.g. Saussure, Morris). I focus on Peirce's for the following reasons: (1) Compared to other accounts, Peirce's is the most developed, elaborate and flexible account of signs and semiosis, and it is compatible with pragmatism. (2) Its explanatory power is greater - it can be used for a full-fledged interpretation and thorough analysis of any sign. (3) His system is backed up by his thorough studies in history, logic and science. As a result he elaborated classifications of signs for the analysis of signs.

10 It is noteworthy that the interpretant, according to Peirce, has a dual nature - it is both a meaning and the sign itself (CP 2.228). So, the meaning of a sign also signifies something for a subject, i.e. it is a sign itself.

11 The term 'intentionality' is overloaded and ambiguous in cognitive sciences and philosophy. Leaving aside detailed discussions about the nature of intentionality or whether it can legitimately be ascribed to mental states, I will use this term to denote the "aboutness" of mental states, i.e. a mental state as being about something or standing for some object. Thus, I take it as an implicit premise that mental states are intentional in the sense stated above. 
something or stands for something. Thus, just as signs, mental images have objects that those images represent. The object of a mental image need not be previously experienced but currently absent. The image can concern situations, properties, experiences, states or feelings. Images can be detached from external reality in the sense of representing, say, non-physical objects of fiction. But in any case a mental image "stands for something" (CP 2.228), i.e. it represents ${ }^{12}$ an object.

Second, an image also has something that enables it to represent its object. In other words, an image should have some sort of a ground element or, in Morris's terms, a sign vehicle. The ground of the sign is the element that represents or stands for its object in some meaning. Peirce says that "a sign stands for [its] object, not in all respects, but in reference to some sort of idea, which I have sometimes called the ground of the [sign]" (CP 2.228). He also calls this element a representamen, since this part of the sign represents (in the broadest possible sense) its object in some meaningful relation. Since an image necessarily stands for some object, it follows that the image should necessarily have this ground element which would represent its object. In this respect, an image is a sign.

Finally, the relation of representation between sign vehicles and objects of an image should be meaningful to the subject of the image. Hence, as a sign, a mental image has an interpretant. An image stands for some object in "some respect or capacity" (CP 2.228). Clearly mental images have content. They convey some meaning from a single property to complex networks of signification. When voluntarily using imagery, we tend to interpret our mental images as meaning something. Furthermore, it appears that even our largely involuntary images - dreams - during sleep can be interpreted after they have occurred. In this sense every mental image has a meaning, produced as a result of (co)relation with its object and interpreted by the subject.

To summarize, a mental image necessarily stands for some object. It also has the ground element or representamen that enables the representation of this object. And as a result of the correlation between representamen and object, the meaning or interpretant of an image is produced. So, a mental image has the same structure as the sign and the (general) definition of the sign and thus can legitimately be interpreted as a sign. Just as a sign, a mental image consists of the three basic elements - representamen, object and meaning. Hence, just as a sign a mental image can be defined as "something which stands to somebody for something in some respect or capacity", an image is formed and should be interpreted in the context of the signifying (or semiotic) process

12 It is in this sense that mental imagery is usually associated with the term "mental representation". In brief, any representation has an object which it represents. By contrast, the two dominant accounts on MI agree about the existence of some sort of representation in the mind (i.e. they share the representational paradigm as a premise); what they disagree about is exactly how these representations represent their objects, i.e. which format of representation is used to represent an object. 
and inside the network of sign relations. Based on these, the basic structure of a mental image is schematically depicted in Fig. 1.

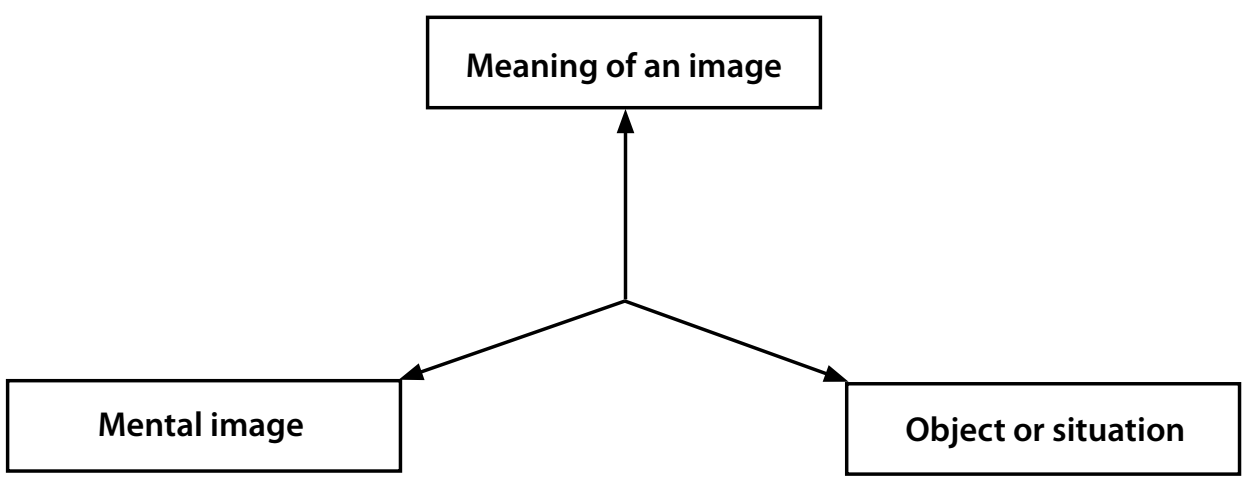

Figure 1. Structure of an image.

A characterization of mental imagery as a sign system has far-reaching consequences. This approach can, I believe, accommodate various properties of mental images into one coherent explanatory theory. It can reconcile divergent views and contesting empirical evidence and even provide further understanding of cognitive mechanisms of MI in the human mind. So far I have described the sign theory in general terms, but a closer examination is to view mental imagery as a sign system.

\subsection{Analysis of mental imagery in terms of signs: An example}

Peirce's sign theory amounts to a system of various classes of signs, the development of which was never fully completed though it occupied much of this time. As a result, comprehensive classifications of signs were produced. The general structure of the sign consists of three basic elements. According to Peirce, if we analyse each of the elements and the features they might have, we can get ten different classes of signs: "signs are divisible by three trichotomies; first, according as the sign in itself is a mere quality, is an actual existent, or is a general law; secondly, according as the relation of the sign to its object consists in the sign's having some character in itself, or in some existential relation to that object, or in its relation to an interpretant; thirdly, according as its Interpretant represents it as a sign of possibility or a sign of fact or as a sign of reason" (CP 2.243). Each of the three sign elements - sign (vehicle), object and interpretant are divided into three sub-types. Peirce calls the first of the three trichotomic divisions 
qualisigns, sinsigns and legisigns (CP 2.244), the second icons, indexes and symbols (CP 2.247) and the third rhemes, dicisigns and delomes (CP 2.250). Together, the relationships between these three trichotomies give rise to the 10 classes $^{13}$ of signs.

Once applied to analyse MI, this detailed account of sign theory and the ten classes of signs suggest a subtle and full-fledged explanation of the mental-imagery phenomenon. I propose to test the hypothesis. Consider the following example of the usage of mental imagery in ordinary daydreaming:

Imagine yourself experiencing the scent of a rose in the garden. You go out the back door of your house to enter the garden behind the house. You stand on the terrace, and while looking on the garden, imagine that you have the sensation of a flower scent. You don't yet see the roses, but you feel the subtle, sweet flower scent and you recognize this scent immediately as being a smell signifying that somewhere near roses grow.

How to analyse this simple daydream? I claim that MI is exhaustively explained in terms of signs. The example produces a compound image that consists of several elements and conveys a complex meaning. First, image as the sign vehicle represents an object of a particular quality - a smell. Thus the representamen of the image is a qualisign. But exactly what does the smell represent? The object of signification in the imaginary case stated above is a rose. A subtle and sweet smell is a sign of the presence of a rose in the garden. Hence, the rose is an existential actual object that is represented in the image. In relation to the object of the image that sign is an index. Finally, what is the signification of the image? What does it mean? The immediate interpretant that was conveyed by the image is the recognition of the subtle, sweet sensation as that of a rose's smell. Our understanding of the image focuses on the qualitative feature (smell) of the object represented (rose). From the sign-interpretant relationship we get that the image is a rheme.

This is a simple analysis of the example in terms of signs. But Peirce pointed out that there are no "pure" types of signs in our ordinary cognition. Usually every sign displays some combination of various characteristics. Thus, the analysis of the imaginary example continues, and more subtle characteristics and inter-relations between elements of the image might be uncovered. The sign vehicle also has the properties of a sinsign, namely existential properties. The quality - smell of a rose - is causally connected with

13 Initially, the three thrichotomies yield twenty-seven possible classes. But Peirce has further phenomenological constraints on how we combine the different elements of the sign. As a result, only ten permissible classes remain. In his later work, Peirce expanded the list of trichotomies and suggested more complex classifications of the signs, such as the sixty-six classes of signs. This later classification will not be discussed, mainly for two reasons: (1) Peirce did not complete that work, and his ideas remained conjectural; (2) the detailed discussion of the nature and derivation of classifications would in any case fall out of the scope of the present paper. My aim is to show that the mental-imagery phenomenon can be legitimately interpreted as a sign system. 
the object - a rose. In other words, there is a subtle and sweet smell only if there is a rose. The existence of an object is the cause of your sensation of the smell. In this sense the sign vehicle represents not only as quality (smell) but also as the causal co-location (smell-rose). Thus the representamen has the properties of a sinsign.

Further, as regard its object (rose), an exemplary image also has iconic features. For example, in my dream I visualize a particular flower which resembles the real object of the outside world. If so, the object is represented in the image as an icon, since it is similar to the real object of the external world in the way it looks, smells or grows. When I dream about the rose, I might visualize those particular sizes, shapes, textures and colours. The image rich in such information possesses iconic features. And at the same time, my recognition of the presence of the rose in the garden remains indexical. The smell of a rose is an index of the presence of a rose: these two facts are interrelated, causally connected. If there is the smell of a rose in the garden, then somewhere in this garden a rose should grow.

Finally, the meaning of this imaginary experience can also be manifold. In regard to its interpretant an exemplary image can convey not only the immediate meaning of olfactory sensation (rheme), but also have an existential interpretant (dicent). The very first meaning that one will get about the image is, of course, the interpretant of a feeling, or as Peirce sometimes calls it, an emotional interpretant. The smell of the rose is immediately felt when I imagine myself going into the garden. It is directly given, immediately felt and recognized by the subject. At this stage this first recognition of the particular quality and immediate experience of this quality (the smell in our example) is not reflected upon yet, or as one might put it, is pre-reflective. This is the first interpretant of my image, a rheme.

But once I have reflected upon my immediate sensation of a sweet and subtle smell, I realize that if there is (i.e. exists) this sweet and subtle smell of a rose, then there also should be a rose itself as the carrier of this quality. This is already an analysed understanding of the existential relation between quality and object that goes beyond immediate meaning. If we accept the reflected or analysed meaning of the quality then the sign signifies the existence of a particular object (rose). Thus the interpretant of an exemplary image can also take the form of the dicent or energetic interpretant, namely the interpretant of the existential fact.

Next, the above-described imaginary experience seems to convey further meaning that goes beyond emotional and existential interpretants. The exemplary image also has the features of a delome, the conventional interpretant. The imaginary experience of feeling the smell of a rose uncovers a rule or habit that lies dormant in the situation. In the imaginary example the subject infers the existence of the rose from the presence of the particular smell only because he possesses the conventional (and often implicit) 
knowledge ${ }^{14}$ about where the roses grow, for example. In my dream, I imagined entering the garden to feel the smell of a rose, not some other place such as a seashore or a forest. Why is that? Because it is a general but fallible rule that roses grow in the garden. Thus, the imagined experience of smelling the rose is based on tacit knowledge shared by all. Moreover, the algorithm of my imagined actions - to go to the countryside, to enter the countryside house, to open the back door into the garden, to enter the terrace - is also conventional. It is based on the knowledge where the garden might be located, how to enter the garden, what one should do to have an olfactory sensation of a rose, etc. Without this tacit knowledge the co-relation of some elements of the image (smellrose in our case) would be impossible. Furthermore, a dreaming subject might evoke some natural language in his daydream of sensing the smell of a rose. For example, verbal language might be used to signify the logical sequence of the imagined actions or other details of the dream. In this case, the interpretation of the exemplary image has conventional characteristics.

To sum up, in our example the signification of the object (rose) by the sign vehicle (smell) generates a compound meaning which consists of emotional, existential and conventional interpretants.

\section{Conclusion}

My case study of MI proposes two points: (1) mental imagery can legitimately be interpreted in terms of Peirce's theory of signs; and (2) such an interpretation suggests fruitful prospects to understand MI phenomena from new theoretical points of view. The nature and function of mental images ultimately can, I argue, be understood in that wider context of signification procedures, the three relata of the sign and the interesting relations between them. Representational paradigms that underlie dominant accounts on MI are limited in taking stock of the importance of relational elements.

MI constitutes a complex system of signs. Images exhibit features with complex meaning. The analysis of an imaginary mental image in terms of signs proposes that MI has properties of all three trichotomies of the signifying relata. Moreover, various properties of images can co-exist with each other, enabling a coherent and multilevel analysis of MI. Though a further investigation of such an account of MI as a sign system is needed, even these preliminary considerations warrant the proposed method of analysis.

14 Conventional or implicit knowledge about the world is often termed 'tacit' in cognitive science. Pylyshyn has interpreted imagery experiments (e.g. mental scanning, mental rotation, mental mapping etc.) as those guided by tacit knowledge by the subjects experimented on about how things would have been if perceived in reality and not just imagined (see, e.g., Pylyshyn 2002). 


\section{References}

Bartolomeo, Paolo 2002. The relationship between visual perception and visual mental imagery: A reappraisal of the neuropsychological evidence. Cortex 38(3): 357-378.

- 2008. The neural correlates of visual mental imagery: An ongoing debate. Cortex 44(2): 107-108.

$\mathrm{CP}=$ Peirce 1931-1958.

Fodor, Jerry A. 1975. The Language of Thought. Cambridge: Harvard University Press.

Glasgow, Janice; Papadias, Dimitri 1992. Computational imagery. Cognitive Science 16(3): 355-394.

Keller, Peter E. 2012. Mental imagery in music performance: Underlying mechanisms and potential benefits. New York Academy of Sciences Apr 1252: 206-213.

Kosslyn, Stephen M. 1980. Image and Mind. Cambridge: Harvard University Press.

- 1988. Aspects of a cognitive neuroscience of mental imagery. Science (New Series) 240(4859): 1621-1626.

- 1994. Image and Brain: The Resolution of the Imagery Debate. Cambridge: The MIT Press.

Kosslyn, Stephen M.; Thompson, William L. 2003. When is early visual cortex activated during visual mental imagery? Psychological Bulletin 129(5): 723-746.

Kosslyn, Stephen M.; Ganis, Giorgio; Thompson, William L. 2006. Mental imagery and the human brain. In: Jing, Qicheng et al. (eds.), Progress in Psychological Science Around the World. Vol. 1: Neural, Cognitive and Developmental Issues. London: Psychology Press, 195-209.

Pascual-Leone, Alvaro; Nguyet, Dang; Cohen, Leonardo G.; Brasil-Neto, Joaquim P.; Cammarota, Angel; Hallett, Mark 1995. Modulation of muscle responses evoked by transcranial magnetic stimulation during the acquisition of new fine motor skills. Journal of Neurophysiology 74(3): 1037-1045.

Peirce, Charles S. 1931-1958. Collected Papers of Charles Sanders Peirce. Cambridge: Harvard University Press. (Electronic ed., intr. by Deely, John; reproducing vols. I-VI of the ed. by Hartshorne, Charles; Weiss, Paul. Cambridge: Harvard University Press, 1931-1935).

Pylyshyn, Zenon W. 1973. What the mind's eye tells the mind's brain: A critique of mental imagery. Psychological Bulletin 80: 1-24.

- 2002. Mental imagery: In search of a theory. Behavioral and Brain Sciences 25(2): 157-238.

- 2003. Seeing and Visualizing: It's Not What You Think. Cambridge: The MIT Press.

- 2006[2004]. Imagery. In: Gregory, Richard L. (ed.), Oxford Companion to the Mind (2nd ed.). Oxford, New York: Oxford University Press.

Richardson, Peggy A. 1995. Therapeutic imagery and athletic injuries. Journal of Athletic Training 30(1): 10-12. 


\section{Теория знаков в действии: снова о дебатах по поводу ментальных образов}

В статье я стараюсь дать приемлемое объяснение сущности ментальных образов, которая была предметом долгих споров. Традиционный подход к этому вопросу основан на репрезентационной парадигме, которая, по моему мнению, ошибочна. Вместо репрезентационных аспектов ментальных образов я выделяю функции ментальных образов, множество различных характеристик, проявляемых ментальными образами в экспериментальных исследованиях, а также отношения между разными свойствами образов, их функциями и субъектами образов. Предлагаю рассмотреть ментальный образ как знаковую систему, состоящую из разных типов знаков. Так, ментальный образ может содержать важные свойства как части комплексного знака. Такой подход к объяснению ментальных образов представляется продуктивным, поскольку он позволяет разрешить некоторые из давних споров по данному вопросу.

\section{Märgiteooria toimimises: taas mentaalsete kuvandite debatist}

Käesolevas artiklis püütakse anda usutav seletus pikki vaidlusi põhjustanud küsimusele mentaalsete kuvandite olemusest. Traditsiooniline lähenemine sellele küsimusele põhineb representatsioonilisel paradigmal, mis minu väitel on ekslik. Mentaalsete kuvandite representatsiooniliste aspektide asemel rõhutan mentaalsete kuvandite funktsioone, eksperimentaalsetes uuringutes kuvandite poolt üles näidatavate omaduste mitmekesisust ning kuvandite erinevate tunnuste, nende funktsioonide ja kuvandite subjekti vahelisi suhteid. Pakun välja, et mentaalset kuvandit võib vaadelda erinevatest märgitüüpidest koosneva märgisüsteemina. Mentaalne kuvand võib sisaldada olulisi omadusi, mis on kompleksse märgi osadeks. See lähenemine mentaalsete kuvandite olemusele on kasulik, sest viitab mentaalse kujundistiku fenomenile, mis aitab ületada mõningaid kaua kestnud vasturääkivusi sel teemal. 